\title{
FREQUENCIES OF FELINE BLOOD TYPES IN HUNGARY
}

\author{
Nóra BAGDI $^{1 *}$, Melinda MAGDUs ${ }^{2}$, E. LEIDINGER ${ }^{3}$, Judith LEIDINGER ${ }^{3}$ and K. VÖRÖS ${ }^{1}$ \\ ${ }^{1}$ Department and Clinic of Internal Medicine, Faculty of Veterinary Science, Szent István \\ University, H-1400 Budapest, P.O. Box 2, Hungary; ${ }^{2}$ Private practitioner, Budapest, \\ Hungary; ${ }^{3}$ Veterinary Laboratory Invitro, Vienna, Austria
}

(Received March 9, 2001; accepted September 5, 2001)

\begin{abstract}
Feline blood group determination is done as a routine diagnostic method in numerous countries. Blood transfusion reactions and feline neonatal isoerythrolysis (FNI) can be avoided with the identification of different feline blood groups. The present study is the first investigation in Hungary during which 100 cats have been examined from all over the country. These cats were out of six breeds: European domestic shorthair, Persian mix, Persian, Abyssinian, Siamese and British shorthair. In the Hungarian feline population European domestic shorthair are most common but other breeds also occur. European domestic shorthair, Persian mix, Abyssinian, Siamese and British shorthair individuals all belonged to blood type A (100\%). Blood type B was found very rarely and only in Persian cats. Onethird of the Persian cats were categorised into blood type B, whilst type AB was not found during the study.
\end{abstract}

Keywords: Feline, blood types, transfusion, neonatal isoerythrolysis

The identification of alloantibodies provided the first evidence of a feline blood group system at the beginning of the 20th century (Ingebrigsten, 1912; Ottenburg and Thalhimer, 1915). Eyquem and Podliachouk (1954) discovered two antigens on the surface of red blood cells: the so-called type A and B (Ejima et al., 1986). Auer and Bell found an additional blood type known as blood type AB (Auer et al., 1982).

Similar to humans, but unlike other animals, cats have preformed alloantibodies. All type B cats older than 3 months have strong anti-A antibodies in their blood. In contrast, only $35 \%$ of type A cats possess anti-B antibodies that are generally weak (Giger, 1992; Bücheler and Giger, 1993; Hubler et al., 1993; Knottenbelt et al., 1999).

In the $\mathrm{AB}$ blood group system, the only known system in cats, the allele $\mathrm{A}$ is dominant over the allele $\mathrm{B}$. The $\mathrm{AB}$ allele is very rare, behaves like a third allele, and is recessive to the A allele, but dominant over the B allele (Griot-Wenk et al., 1996).

\footnotetext{
*Corresponding author; Dr. Nóra Bagdi, H-1076 Budapest, Thököly út 4. II. 26, Hungary; E-mail: bagdiparti@freemail.hu; Fax: +36 (1) 351-5276
} 
Recognition of the feline blood types is clinically important in avoiding acute haemolytic transfusion reactions (so-called 'transfusion accidents') (Giger, 1992; Griot-Wenk and Giger, 1995) and feline neonatal isoerythrolysis (FNI) also known as haemolysis of the newborn.

Haemolytic transfusion reactions occur when type A blood is administered to type $\mathrm{B}$ cats or type $\mathrm{B}$ blood is given to a type A or AB cat. In case of a 'transfusion accident' the following symptoms can occur: fever, vomiting, hypopnoea, hypotonia, bradycardia, unconscious defecation and urination, haemolysis and pigmenturia. In severe cases the patient may die acutely (Auer and Bell, 1983; Giger et al., 1991).

Feline neonatal isoerythrolysis (FNI) (Stormont, 1975; Hubler et al., 1987; Giger, 1991) occurs in newborn type A or AB kittens born to type B queens after colostrum intake during the first day of life and is characterized by lysis of red blood cells (Hubler et al., 1987; Giger and Casal, 1997; Leidinger and Leidinger, 1997).

FNI can occur when the queen's blood type is B and the tom has blood type A (genotype is $\mathrm{A} / \mathrm{A}$ or $\mathrm{A} / \mathrm{B}$ ); the kittens will have blood type A (genotype $\mathrm{A} / \mathrm{B}$ ) or $\mathrm{B}$ (genotype $\mathrm{B} / \mathrm{B}$ ). The anti-A antibodies in the colostrum of type $\mathrm{B}$ queens can be absorbed during the first 16 hours and attack the kitten's erythrocytes. Haemoglobinuria, icterus, anaemia, and often death will follow (Giger et al., 1991). FNI does not occur in type B kittens born to type A or B queens.

Blood type incompatibilities can be avoided if the blood type of donor and patient or the parents are known. Thus if the queen belongs to blood type B and the kittens have blood type A, kittens should not be allowed to nurse from the queen. In this case, kittens have to be fed a milk replacer for the first day of their life, or they could be nursed by a type A foster queen. Breeders should be encouraged to have cats blood typed before breeding.

According to recent surveys, incompatibility reactions are expected to occur in any breeds with type B blood. Except for the Siamese, Tonkinese, Burmese and Russian Blue cats which have all type A blood, all other breeds have varied type B frequencies (Giger, 2000).

Distribution of blood types of the domestic shorthair cat has been studied in the USA, Australia, Argentina and several countries in Europe (Giger, 2000). The aim of this study was to determine the frequency of feline blood types in Hungary in a small group of cats.

\section{Materials and methods}

Blood from a total of 100 cats from 6 different breeds from all 4 parts of the country were examined. Blood from the v. antebrachii or from the v. jugularis was aseptically collected in EDTA or heparin tubes and stored at $4{ }^{\circ} \mathrm{C}$ for up to one week until blood typing. 
During our studies the method of Giger as modified by Leidinger was performed in microtitre plates (Leidinger et al., 1993). Triticum vulgaris (T. V.) lectin as anti-B and anti-A antibodies from type B cats were used for the haemagglutination reaction. Agglutination was recorded after 15-min incubation as positive or negative. T. V. lectin (Sigma, Cat. Nr. L-9640), 0.9\% NaCl solution, PBS solution $(0.01 \mathrm{M})$ and Anti-A serum (from cats of blood group B) were used.

Blood type A and B determination was performed as follows:

- preparation of red cell suspension: the plasma was separated from the red blood cells by centrifugation;

- the plasma was stored at $-20{ }^{\circ} \mathrm{C}$;

$-250 \mu \mathrm{red}$ blood cells were added to $4 \mathrm{ml} 0.9 \% \mathrm{NaCl}$ solution;

- the suspension was mixed, centrifuged and the upper part was discarded;

$-50 \mu \mathrm{l}$ red blood cells were put into $950 \mu \mathrm{l} 0.9 \% \mathrm{NaCl}$ solution (resulting in a $3-5 \mathrm{v} / \mathrm{v} \%$ suspension);

- haemagglutination reaction: in a ' $U$ '-shaped microtitre plate $40 \mu 1$ anti-A serum was transferred into the wells of the first row, $40 \mu \mathrm{l}$ lectin T.V. into the plates of the second row, and $40 \mu 10.9 \% \mathrm{NaCl}$ (negative control) into the wells of the third row. Twenty $\mu$ of the $3-5 \mathrm{v} / \mathrm{v} \%$ blood cell suspension was added to each well. The plate was carefully agitated and incubated for 20 or $30 \mathrm{~min}$ at room temperature. The grade of agglutination was assessed (Table 1). In case a blood group B was found, it was double-checked (repeat testing) when 2 drops of the unknown serum were put into $40 \mu \mathrm{l} 0.9 \% \mathrm{NaCl}$ and $20 \mu \mathrm{l} 3-5 \mathrm{v} / \mathrm{v} \% \mathrm{red}$ blood cell suspension. The two components were mixed carefully together, incubated at room temperature for $15 \mathrm{~min}$, and the grade of the agglutination was examined macroscopically or microscopically.

Table 1

Evaluations of the agglutination reactions for blood typing

\begin{tabular}{|c|c|c|c|}
\hline \multicolumn{3}{|c|}{ Agglutination } & \multirow{2}{*}{$\begin{array}{r}\text { Interpretation } \\
\text { Blood type }\end{array}$} \\
\hline Anti-A serum & Lectin T.V. & $0.9 \% \mathrm{NaCl}$ & \\
\hline++++ & negative & negative & A \\
\hline negative & & negative & B \\
\hline positive & positive & negative & $\mathrm{AB}$ \\
\hline
\end{tabular}

\section{Results}

Altogether 100 cats were examined in Hungary in 1997. Six breeds were represented: 73 European domestic shorthair, 8 Persian mix, 9 Persian, 6 Abyssinian, 3 Siamese and 1 British shorthair. There were 38 tom cats, 13 castrated cats, 40 intact females and 9 spayed cats. Their ages varied from 8 months to 13 
years. The cats originated from 4 parts of the country: 54 from Budapest, 28 from Transdanubia, 4 from Eastern Hungary east of the river Tisza, and 14 from the area between the rivers Danube and Tisza.

Table 2 demonstrates the blood type distribution according to the six different breeds. All of the European domestic shorthair, the house cats in Hungary, had blood type A. Also all Persian mix, Abyssinian, Siamese and British shorthair had blood type A $(100 \%)$. However, 3 of the nine Persian cats had blood type B (33\%).

Table 2

Blood type and breed distribution of the examined cats during the present study

\begin{tabular}{|c|c|c|c|c|c|c|}
\hline \multirow{2}{*}{ Breeds } & \multicolumn{2}{|c|}{ Studied cats } & \multicolumn{2}{|c|}{ Cats with blood type A } & \multicolumn{2}{|c|}{ Cats with blood type B } \\
\hline & no. of cats & $\%$ & no. of cats & $\%$ & no. of cats & $\%$ \\
\hline Domestic shorthair & 73 & 73 & 73 & 100 & 0 & 0 \\
\hline Persian mix & 8 & 8 & 8 & 100 & 0 & 0 \\
\hline Persian & 9 & 9 & 6 & 66 & 3 & 33 \\
\hline Abyssinian & 6 & 6 & 6 & 100 & 0 & 0 \\
\hline Siamese & 3 & 3 & 3 & 100 & 0 & 0 \\
\hline British shorthair & 1 & 1 & 1 & 100 & 0 & 0 \\
\hline Total & 100 & 100 & 97 & 97 & 3 & 33 \\
\hline
\end{tabular}

The strength of the haemagglutination reaction was ++ in $10 \%$ of the cats, +++ in $10 \%$ of the cats and ++++ in $80 \%$ of type A cats, and + in $33 \%$ and ++ in $66 \%$ of type B cats.

Of the three Persians with blood type B, two were intact females (one had been used for breeding) and one was a castrated male, whereas the 6 Persians with blood type A included 4 intact females, a spayed female and a castrated male.

The majority of the examined cats were from Budapest (54\%). They were European domestic shorthair, Abyssinian, Siamese and British shorthair. Two of the Persians (4\%) from Budapest were classified as blood group B. The rest of the cats (European domestic shorthair, Abyssinian, Siamese and British shorthair) had blood type A (96\%). The third cat belonging to blood group B was from the area between the Danube and the Tisza.

\section{Discussion}

We found the haemagglutination method using a microtitre plate (Giger, as modified by Leidinger) reliable and simple to determine blood type A and B. Triticum vulgaris lectin readily agglutinated type B blood cells and anti-A serum from type B cats agglutinated type A cells. 
In our study half of the 100 cats studied in Hungary were from Budapest. The 100 cats were out of six breeds: European domestic shorthair, Persian mix, Persian, Abyssinian, Siamese, and British shorthair. The cats represented several different breeds. European domestic shorthair is the predominant breed in the Hungarian cat population and thus most of the blood samples (73\%) in this study originated from these domestic cats.

Of the non-pedigree cats (in this case: European domestic shorthair and Persian mix) $100 \%$ were blood type A, of the purebred cats $84.2 \%$ were type A, $15.8 \%$ were type $\mathrm{B}$ and $0 \%$ were type $\mathrm{AB}$. The majority (47\%) of these purebred cats were Persian of which $66 \%$ were type A and 33\% were type B. We found that purebred cats with blood type B occur in Hungary, demonstrated by the two female Persian cats and one castrated male belonging to blood type B. The results of the present study concerning the distribution of the blood types in different breeds were similar to those reported from other countries. Similar to other parts of the world the predominant blood type was type A. In fact all 73 domestic shorthair cats mostly from Budapest had type A blood. Because the number of tested domestic shorthair cats in Hungary was small, it cannot be concluded that all domestic shorthair cats in Hungary have blood type A. It is recommended to do typing before transfusing cats.

Similarly, in Switzerland 1014 domestic shorthair cats have been blood typed. Of them $99.6 \%$ had blood type A and $0.4 \%$ had blood type B, with no type AB cats detected (Hubler et al., 1993). In Germany blood type A occurred most frequently (92\%), type B was seen in 7\% and type $\mathrm{AB}$ was extremely rare with 1\% (Haarer and Grünbaum, 1993). In Austria 217 cats have been tested. 193 (88\%) of them had blood type A, 24 (12\%) had blood type B and no type AB cats were found (Leidinger et al., 1993). In the USA most domestic shorthair cats had blood type A, a few had blood type B, and very few had blood type AB (Giger et al., 1991). There are several breeds with a high frequency of type B blood such as Devon Rex (41\%), Cornish Rex (33\%), British shorthair (36\%) and Exotic shorthair (27\%) (Giger, 2000). In Denmark 244 cats have been tested and 93\% of all cats had blood type A, 7\% were type B and type $\mathrm{AB}$ were found in $0 \%$ of the cases (Jensen et al., 1994).

The discovery of two female and one male Persian cats with type B blood is particularly important. Because type B queens are at risk to have litters with FNI when bred to type A toms, our results are very important for Persian cat breeders. These queens should only be bred to type B toms. If they are bred to type A toms, nursing from the type B queen has to be prevented for 24 hours. Kittens need to be foster-nursed every four hours with milk replacer for cats or placed on a type A queen that recently had a litter. Feline milk and colostrum contain similar quantities of maternal antibodies. 
Based upon this limited survey we conclude that European domestic cats in Hungary have all type A blood and that the proportion of type A and B blood type among purebred cats may be similar to other parts of the world.

Thus, blood typing is particularly indicated whenever a transfusion is made from a European domestic shorthair to a Persian or to an imported Persian.

\section{Acknowledgement}

The authors wish to thank Prof. Dr. Urs Giger, Philadelphia, for the valuable suggestions and review of the manuscript.

\section{References}

Auer, L. and Bell, K. (1981): The AB blood group system of cats. Anim. Blood Groups Biochem. Genet. 12, 287-297.

Auer, L. and Bell, K. (1983): Transfusion reactions in cats due to AB blood group incompatibility. Res. Vet. Sci. 35, 145-152.

Auer, L., Bell, K. and Coates, S. (1982): Blood transfusion reactions in the cat. J. Am. Vet. Med. Assoc. 180, 729-730.

Bücheler, J. and Giger, U. (1993): Alloantibodies against A and B blood types in cats. Vet. Immunol. Immunopathol. 38, 283-295.

Ejima, H., Kurokawa, K. and Ikemoto, S. (1986): Feline red blood cell groups detected by naturally occurring isoantibody. Jpn. J. Vet. Sci. 48, 971-976.

Eyquem, A. and Podliachouk, L. (1954): Les groupes sanguius des chats. Annales de l'Institut Pasteur (Immunol.) 87, 91-94.

Giger, U. (1991): Feline neonatal isoerythrolysis. A major cause of the fading kitten syndrome. Proc. Am. Coll. Vet. Med. 5, 347.

Giger, U. (1992): Feline transfusion medicine. Probl. Vet. Med. 4, 600-611.

Giger, U. (2000): Blood typing and crossmatching to ensure compatible transfusions. Kirk's Current Veterinary Therapy 13, 396-399.

Giger, U. and Casal, M. L. (1997): Feline colostrum - friend or foe - Maternal antibodies in queen and kittens. J. Reprod. Fertil. Suppl. 51, 313-316.

Giger, U., Wilkerson, M. and Meyers, K. (1991): Two cat colonies with A and B blood types and clinical transfusion reaction. Feline Practice 19, 22-26.

Griot-Wenk, M. and Giger, U. (1995): Feline transfusion medicine. Blood types and their clinical importance. Vet. Clin. North Am., Small Anim. Pract. 25, 1305-1322.

Griot-Wenk, M., Callan, M., Casal, M., Chisolm-Chait, A., Spitalnik, S., Patterson, D. and Giger, U. (1996): Blood type AB in the feline AB blood group system. Am. J. Vet. Res. 57, 14381442.

Haarer, M. and Grünbaum, E. G. (1993): Blood group serology in cats in Germany. Kleintierpraxis 38, 195-204.

Hubler, M., Arnold, S., Casal, M., Fairburn, A., Nussbaumer, M. and Rusch, P. (1993): The blood group distribution in domestic cats in Switzerland. Schweiz. Arch. Tierheilk. 135, 231-235.

Hubler, M., Kaelin, S., Hagen, A., Fairburn, A., Canfield, P. and Ruesch, P. (1987): Feline neonatal isoerythrolysis in two litters. J. Small Anim. Pract. 28, 833-838. 
Ingebrigsten, R. (1912): The influence of isoagglutinins on the final results of homoplastic transplantation of arteries. J. Exp. Med. 16, 169-177.

Jensen, A., Olesen, A. and Arnbjerg, J. (1994): Distribution of feline blood types detected in the Copenhagen area of Denmark. Acta Vet. Scand. 35, 121-124.

Knottenbelt, C. M., Addie, D. D., Day, M. J. and Mackin, A. J. (1999): Determination of the prevalence of feline blood types in the USA. J. Small Anim. Pract. 40, 115-118.

Leidinger, E. and Leidinger, J. (1997): Ein Fall von Feliner Neonataler Isoerythrolyse bei einem Britisch Kurzhaar-Welpen. Wien. Tierärztl. Mschr. 84, 53-55.

Leidinger, J., Leidinger, E. and Giger, U. (1993): Verteilung und Bedeutung der Blutgruppen A und B bei Haus- und Rassekatzen in Österreich. Wien. Tierärztl. Mschr. 80, 10-14.

Ottenburg, R. and Thalhimer, W. (1915): Studies in experimental transfusion. J. Med. Res. 28, 213229.

Stormont, C. (1975): Neonatal isoerythrolysis in domestic animals. A comparative review. Adv. Vet. Sci. Comp. Med. 19, 23-45. 